\title{
Impact of Meteorological Parameters on Distribution of Pulmonary Tuberculosis in the City of Yaoundé, Centre Region of Cameroon
}

\author{
Serges Tchatchouang ${ }^{1,2}$, Anne Laure Wetewale ${ }^{1,2}$, Jean Claude Tedom ${ }^{1}$, \\ Emmanuel Tekwu Mouafo ${ }^{1}$, Larissa Kamgue Sidze ${ }^{1}$, Jean Paul Assam-Assam ${ }^{1,3,}$, \\ Veronique Penlap Beng ${ }^{1,2}$ \\ ${ }^{1}$ Biotechnology Centre of Nkolbisson, Laboratory for Tuberculosis Research, University of Yaoundé I, Yaoundé, Cameroon \\ ${ }^{2}$ Department of Biochemistry, Faculty of Science, University of Yaoundé I, Yaoundé, Cameroon \\ ${ }^{3}$ Department of Microbiology, Faculty of Science, University of Yaoundé I, Yaoundé, Cameroon
}

Email address:

assamjean@yahoo.fr (J. P. Assam-Assam)

${ }^{*}$ Corresponding author

\section{To cite this article:}

Serges Tchatchouang, Anne Laure Wetewale, Jean Claude Tedom, Emmanuel Tekwu Mouafo, Larissa Kamgue Sidze, Jean Paul AssamAssam, Veronique Penlap Beng. Impact of Meteorological Parameters on Distribution of Pulmonary Tuberculosis in the City of Yaoundé, Centre Region of Cameroon. Central African Journal of Public Health. Vol. 5, No. 2, 2019, pp. 77-82. doi: 10.11648/j.cajph.20190502.13

Received: August 30, 2018; Accepted: October 30, 2018; Published: March 11, 2019

\begin{abstract}
Tuberculosis remains a major health problem and particularly in the Centre Region of Cameroon where prevalence is still high in the city of Yaoundé. Climate has been proved to have impact on tuberculosis distribution. This study aimed at assessing possible association of TB notifications with some meteorological parameters. Daily, weekly, monthly and quaterly aggregates of tuberculosis diagnosis results for consecutive tuberculosis patients tested over one year (April 2010 until March 2011) at Jamot Hospital of Yaoundé were analysed (Microsoft excel and SPSS). A total of 665 tuberculosis patients were enrolled at the Jamot Hospital of Yaoundé during the study period. Weekly mean humidity and temperature were related to tuberculosis cases with respectively Pearson correlation coefficients of 0.291 and -0.342 even though the relation was weak. For the relationship magnitude $8.5 \%$ and $11.7 \%$ of the variance in tuberculosis cases were explained by weekly mean humidity and temperature respectively. A Poisson regression predicted more tuberculosis cases following weekly increase of humidity, a statistically significant result with $\mathrm{p}<0.001$. There was $12.1 \%$ decrease in the number of tuberculosis cases for each decrease of temperature per week. However, rainfall had no impact on tuberculosis notifications even though most cases were recorded in rainy season while seasonal index changed over time. In short, tuberculosis notifications showed to be associated to two meteorological parameters: mean ambient temperature and relative mean humidity. The highest peak was in the month of June during the rainy season. Data from this work may contribute to the National Tuberculosis Control Program to model tuberculosis variation from recorded tuberculosis notifications since years in order to find an indicator for better intervention strategies for disease control.
\end{abstract}

Keywords: Meteorological Parameters, Tuberculosis, Yaoundé

\section{Introduction}

Tuberculosis (TB) remains a major global health problem. In 2015, an estimated 10.4 million people developed TB and 1.8 million died from the disease. The case fatality ratio (the global proportion of people with TB who die from the disease) varied from under $5 \%$ in a few countries to more than $20 \%$ in most countries in the WHO African Region [1]. Cameroon is a country with high TB incidence [2] with a high prevalence in the city of Yaoundé (17\%) [3]. Due to the burden of TB, some factors has been shown to be linked to it spread like spatiotemporal changes [4]. Many studies have already been conducted to investigate the influence of climate in the evolution of TB 
in many countries since it is a respiratory infectious disease which shows seasonality $[5,6,7,8,9,10]$. In Cameroon, a similar study was done in the Southern South Western Region of Cameroon in 2006 [11]. Seasonal distribution in TB notifications has been confirmed, offering a variety of possible explanations for the findings [6]. When planning interventions to control a disease, it is essential to understand the burden of the disease [12] and epidemiological reports on the burden of active pulmonary TB patients according to climate and for instance meteorological parameters are scarce in Yaoundé. Indeed, climate in the South-West Region of Cameroon is different from the one in the city of Yaoundé (Centre Region of Cameroon) which is equatorial. It is characterized by the alternation of two dry seasons (long dry season from midNovember to mid-March and a short dry season from July to August) and two rainy seasons (one from mid-March to June and another rainy season from September to midNovember) with an average temperature of $24.3^{\circ} \mathrm{C}$ from 2000 to 2009 , contrast between 16 and $31^{\circ} \mathrm{C}$ depending on the season and $1407.3 \mathrm{~mm}$ of water per year are recorded (data from Department of Meteorology in Yaoundé) not far from what had been reported before [13].

A deep understanding of temporal patterns in disease occurrence and its governing principles is valuable for designing preventive programs for disease control, tracking effectiveness of public health programs, and allocating scarce resources. Understanding the temporal patterns in disease occurrence is valuable for formulating effective disease preventive programs [7]. In the absence of reliable data on TB linked to climate in Yaoundé, a research study must be undertaken in order to plan efforts against this threat. To our knowledge, no study has described the seasonality of TB in Yaoundé, therefore, the present investigation aimed to assess the impact of meteorological parameter variability on the distribution of pulmonary tuberculosis in Yaoundé in a period of one year as a pilot project.

\section{Methodology}

Type, duration and scope of the study

It was a descriptive cross-sectional study for 12 months period from April 2010 to March 2011 in which all the sputa of suspected volunteer patients with pulmonary tuberculosis from the Jamot Hospital of Yaoundé were analysed.

\subsection{Location of Study}

Yaoundé is the political Capital of Cameroon with $2,375,460$ inhabitants and is located in the Centre Region. The climate is characterised by two peaks of rainy seasons in May and October following data from the last ten years (Figure 1). We chose Jamot hospital (Latitude: 3.900092N, Longitude: $11.521117 \mathrm{E}$ ) as our study area since it is reference centre for respiratory diseases in Yaoundé.

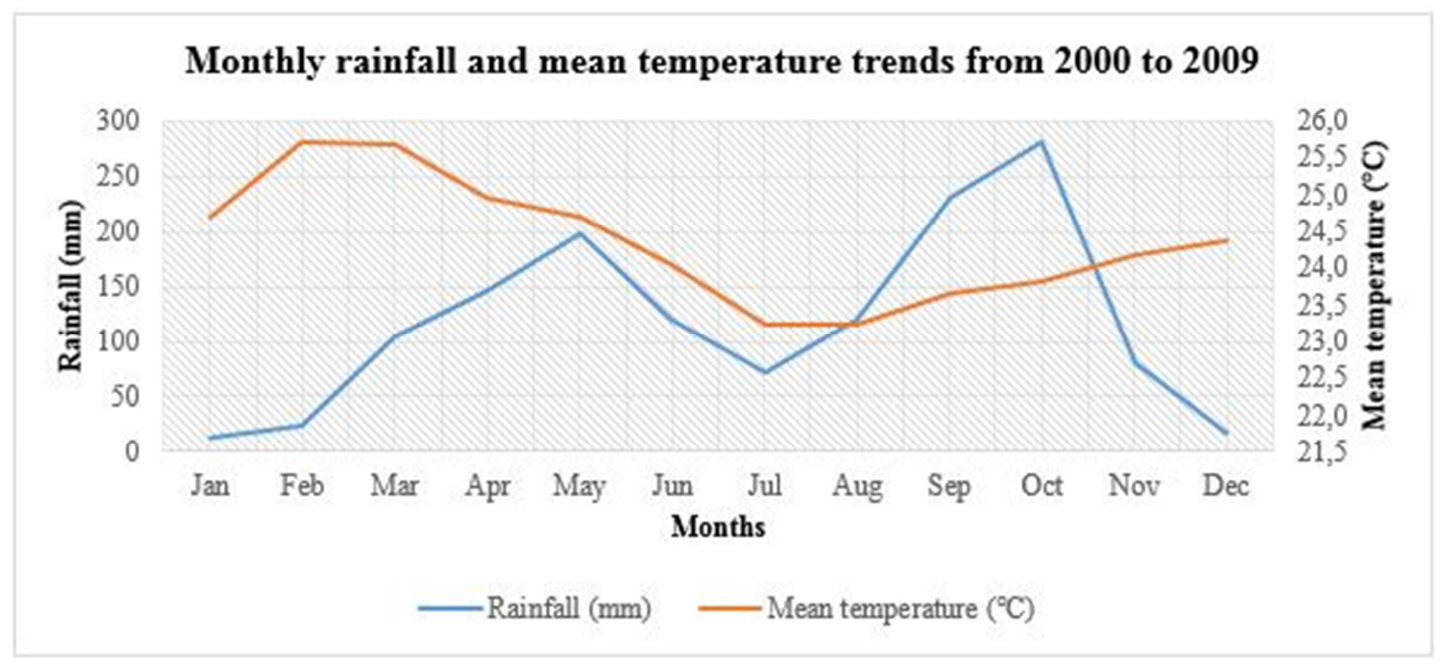

Figure 1. Rainfall and mean temperature trends in Yaoundé from 2000 to 2009 (Cameroon Ministry of Transport, 2009) [14].

\subsection{Target Population}

Our study population consisted of all TB suspects fulfilling the conditions defined below:

Inclusion criteria: it was included in this study sputa of pulmonary tuberculosis suspects of 15 years and older, who agreed to participate in the study.

Non-inclusion criteria: It was not included in this study sputa of TB suspects under the age of 15 years or those over 15 years who refused to give their consent.

\subsection{Ethical Consideration}

This study was in accordance with the ethical standards of the institutional ethics committee. Hence, Ethical Clearance $\mathrm{N}^{\circ} 126 / \mathrm{CNE} / \mathrm{SE} / 09$ and an Administrative Authorization $\mathrm{N}^{\circ} 631.7-10$ were respectively obtained from the Cameroon National Ethic Committee and the Cameroonian Ministry of Public Health. All data collection activities were careful explained before and during the study. Signed informed written consent was obtained from 
each enrolled patient who did not incur any cost for processing of the samples.

\subsection{Data Collection and Processing}

Data on rainfall $(\mathrm{mm})$, mean temperature $\left({ }^{\circ} \mathrm{C}\right)$ and relative humidity (\%) between $1^{\text {st }}$ April 2010 and $1^{\text {st }}$ April 2011 were collected from Department of Meteorology which is accredited for meteorological data collection, documentation and dissemination (Ministry of Transport, Cameroon) at the Station: Yaoundé, Latitude: $3^{\circ} 50^{\prime} \mathrm{N}$ Longitude: $11^{\circ} 31^{\prime} \mathrm{E}$ Altitude: 760,0 M.

Socio-demographic and clinical data were collected from all registered individuals for diagnosis. The handling of sputa was done by Ziehl-Neelsen staining at the recruitment site and confirmed by auramine staining at Centre Pasteur of Cameroon.

\subsection{Compilation of Time Series}

All samples tested for TB contained the date of sample collection; thus the created time series was $100 \%$ complete since.

Possible impact of meteorological parameters on TB was assessed by aggregating the daily surveillance data into a weekly time-series of counts.

Average weekly ambient air temperature and relative humidity readings were then computed for the duration of the time series. The total volume of rainfall for a particular week was calculated using the daily rainfall measurements.

TB episodes were assigned to the week corresponding to the first day of that episode. A week was defined as seven consecutive days from Monday to Sunday, irrespective of any overlap between two calendar years. The first week of January 2010 (January $4^{\text {th }}, 2010$ ) was considered to be the first week of the time-series. Hence, for this study, the weekseries commenced from the $13^{\text {th }}$ week, beginning on March $29^{\text {th }}, 2010$ and ended on the $13^{\text {th }}$ week beginning March $28^{\text {th }}$, 2011.

\subsection{Meteorological Parameters and TB Distribution}

We considered whether there was a relationship between the timing of the peaks of seasonal TB counts and the timing of the peaks of meteorological parameters. We established a time series Poisson regression model to identify the relationship between meteorological parameters and local TB incidence.

\subsection{Seasonal Index}

Seasonal Index (SI) of a period indicates how much this period typically deviates from the annual average. Since we had at least one full season of data which is required for computation of SI [15], we calculated it on monthly and quarterly bases.

\subsection{Statistical Analysis}

Demographic and clinical characteristics of TB patients were described using Chi Square and Fisher's exact tests. The weekly distribution of TB patients and meteorological parameters were graphed, and the relationship was assessed by correlation coefficient. We used Poisson regression to model the number of TB patients as a function of meteorological parameters. Trend of time series were computed by seasonal index. SPSS version 22.0 software was used for correlation to determine the temporal relationship and time series analysis for seasonal variation.

\section{Results}

\subsection{Meteorological Parameters Reported}

Characteristics of the study population were already described [16].

With the seasonal component, the trend in TB cases was apparently decreasing from the $20^{\text {th }}$ week (month of august 2010) to the end of the year (Figure 2).

Two meteorological parameters seemed to explain significant amount of variance in TB cases. Weekly mean humidity and temperature were related to TB cases with respectively Pearson correlation coefficients of 0.291 (positive relationship $\mathrm{r}=0.085$ ) and -0.342 (negative relationship, $\mathrm{r}=0.117$ ) even though the relation was weak.

The magnitude of relationship between weekly mean humidity and amount of TB cases: $8.5 \%$ and $11.7 \%$ of the variance in TB cases are explained by weekly mean humidity and temperature respectively.

A Poisson regression was run to predict the number of TB cases from the study period based on the meteorological parameters (weekly accumulated rainfall, mean temperature and humidity). For every any weekly increase of humidity, 1.035 (95\% CI, 1.017 to 1.053 ) times more TB cases, a statistically significant result, $\mathrm{p}<0.001$. There were a $12.1 \%(\operatorname{Exp}[\mathrm{B}]=$ 0.879 ; $95 \% \mathrm{CI}: 0.829$ to 0.933 ) decrease in the number of TB cases for each decrease of temperature per week. However, we could see that the rainfall was not statistically significant $(\mathrm{p}=$ 0.437; $\operatorname{Exp}[\mathrm{B}]=1,001 ; 95 \%$ CI: 0.999 to 1.003 ). 

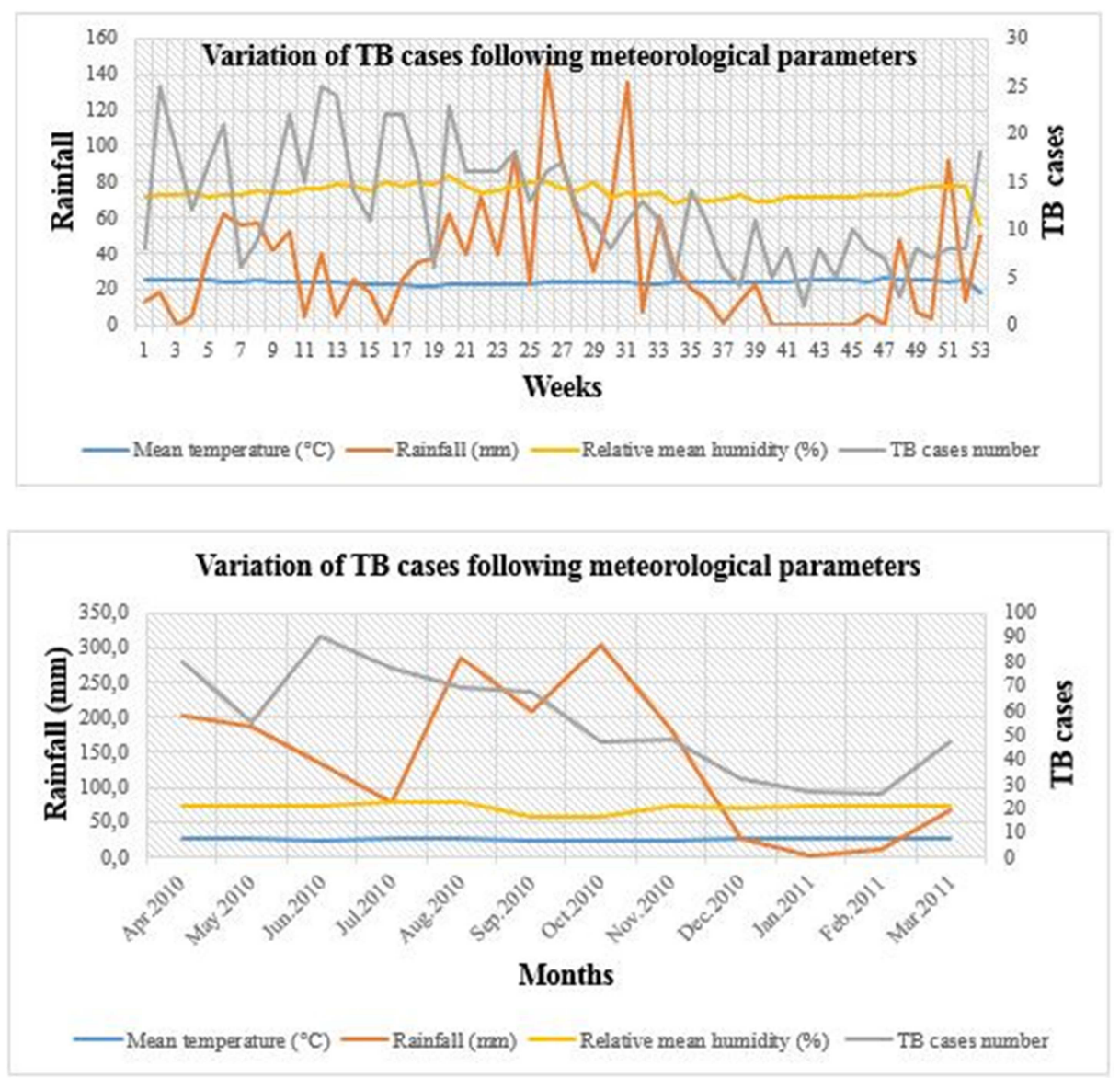

Figure 2. Weekly and monthly trends of TB case numbers over the study period following meteorological parameters reported March $29^{\text {th }}$, 2010 to April $1^{\text {st }}$, 2011 .

\subsection{Seasonal Index}

Over the study period, on monthly basis, $62.2 \%$ increase rate of $\mathrm{TB}$ cases $(\mathrm{SI}=1.62)$ were notified corresponding to the month of June and $53 \%$ decrease of TB cases $(\mathrm{SI}=0.47)$ in September 2010. Overall, the high rate of TB cases was an increase of $35 \%$ for the second quarter of 2010 ( $\mathrm{SI}=1.35$ ) with decrease of $40 \% \mathrm{~TB}$ cases $(\mathrm{SI}=0.6)$ in the first quarter of 2011.

\section{Discussion}

This study aimed to look for impact of three meteorological parameters on the TB cases in Yaoundé: rainfall, mean temperature and relative humidity. Several studies have been conducted on TB distribution based on weather factors mainly in endemic regions and the present one showed variation of TB notifications in Yaoundé following two meteorological parameters: temperature and humidity. Meteorological parameters have been already shown to be linked to respiratory tract infections $[17,18]$ and for instance TB [19]: average temperature [6, 20], humidity $[4]$ and even rainfall $[4,20]$.

Indeed, TB cases increased with relative humidity in this study and it has been suggested that high relative humidity may provide a favourable environment for Mycobacterium to be attached to ambient particulates and stay in the air for a long time. Additionally, high relative humidity can exert profound effects on immunity-oriented problems through restricting the metabolism rate [4]. Conversely, temperature decrease had negative effect on TB notifications by reducing it and is similar to a study in 31 provinces in mainland China [4] and different from a study in Nigeria which is a neighbouring country to Cameroon with similar climatic environment where high pulmonary $\mathrm{TB}$ cases were characterised by low temperature [21]. Hence, high temperature may restrain the development of TB via affecting people's blood pressure, aspiration and biological vitality to increase the infection rate [22]. Also, the recombinant strain of Mycobacterium can stop growing and even could be destroyed when temperature exceeded $37^{\circ} \mathrm{C}$ [23].

Unlike the others (temperature and humidity), measured rainfall was not correlated with circulating TB even though there was a peak in the months of June coinciding with the rainy season in the city of Yaoundé but it was not statistically significant. Seasonal index for the second quarter matched with a rainy season following trends of precipitations in Yaoundé and indicated more TB cases in that period. Previous research in Cameroon has shown peak of TB infection coincides with the rainy season [11] and also another disease due to a mycobacterium (Burili Ulcer) in 
Akonolinga District [24], a neighboring area in the Centre Region of Cameroon.

The weekly and monthly peaks of TB were in $15^{\text {th }}$ (April) and in $26^{\text {th }}$ week (June) of 2010 respectively. On monthly basis, the fact that some patients were diagnosed late or in an advance state of TB can bias the inter month and/or season TB cases. For instance, some who were diagnosed at the beginning of a new season could probably been suffering (infected) since the previous one because it has been noticed that delays in the diagnosis and treatment of tuberculosis are potential stimuli of seasonal tuberculosis disease [25].

Since weak percentage of meteorological parameters explained variance in TB cases, it is important to look for other parameters in further studies. It has been demonstrated elsewhere that the statistical correlation between TB and rainfall may be due to several factors including: increased crowding with increased transmission; some have speculated that the seasonality of TB is mediated by vitamin D levels $[26,27]$. Additionally, indoor activities, seasonal change in immune function, seasonal variation in food availability and food intake, sociodemographic parameters, Regional variation, age, and sex are important factors which can play a role in the tuberculosis notification variability $[8,25]$.

This study has several limitations: although we did not do the comparison with negative cases, thus a possible bias increases in our data. The present analysis was restricted only to sputum smear-positive cases of pulmonary TB.

We collected data only during one year, making it difficult to fully characterize details of seasonality like model prediction test or forecasts for predictions. Understanding TB seasonality may help TB programs to better plan and allocate resources for control activities considering the regularity of peaks of TB seasonality from periodic epidemic model that has already been formulated and studied [7]. Trend and prediction of time series is computed by using Autoregressive Integrated Moving average model [28]. On annual basis, we have only 12 observations and it is assumed at least 50 dealing or observations. More data in many years are needed to develop a model for trends and validate it because one year may be considered too short time for an epidemiologic study. But we think that our preliminary data could provide useful findings for further investigations since these data might induce public health decision-makers to revise the TB prevention policy with regards to the burden of the disease at the national. Prediction model for tuberculosis incidence is needed in Cameroon like in other countries which may be used as a decision supportive tool for planning health interventions and allocating health resources [9].

\section{Conclusion}

The temporal pattern of TB notifications in the city of Yaoundé showed to be associated to two meteorological parameters: mean ambient temperature and relative mean humidity. The highest peak was in the month of June during the rainy season. Data from this work may contribute to the National Tuberculosis Control Program to model tuberculosis variation from recorded tuberculosis notifications since years in order to find an indicator for better intervention strategies for disease control.

\section{List of abbreviations}

Exp [B]: Exponentiation of the B coefficient SPSS: Statistical Package for Social Sciences TB: Tuberculosis

\section{Declarations}

\section{Ethics Approval and Consent to Participate}

This study was approved by the National Ethics Committee of Cameroon and written informed consent was obtained from all participants and/or their parents/legal guardians for children before enrollment.

\section{Consent for Publication}

Not applicable.

\section{Availability of Data and Materials}

The data from the current study is available from the corresponding author on reasonable request.

\section{Competing Interests}

The authors declare that they have no competing interests.

\section{Funding}

This work was supported by European and Developing Countries Clinical Trials Partnership (EDCTP) under project grant $\mathrm{N}^{\circ} \mathrm{CB} .2007 .41700 .006$ via the Central Africa Network on Tuberculosis, HIV/AIDS and Malaria (CANTAM)

\section{Authors' Contributions}

VPB Conceived and designed the study. ST, ALW, EMT and LKS participated in field work.

VPB, JPAA and JCT supervised laboratory analysis. ST analyzed the data. ST, ALW, VPB, JPAA, JCT, EMT and LKS contributed to the writing of the manuscript and approved the final version of the manuscript

\section{Acknowledgements}

Our gratitude goes towards participants without which this study would not have been possible. We appreciated the collaboration received from Jamot Hospital staff and Centre Pasteur of Cameroon.

\section{References}

[1] WHO: Global tuberculosis report. In. Edited by WHO/HTM/TB/2016.13. 20 Avenue Appia, 1211 Geneva 27, Switzerland World Health Organization; 2016. 
[2] Kwedi Nolna S, Kammogne ID, Ndzinga R, Afanda B, Ntone R, Boum Y, Nolna D: Community knowledge, attitudes and practices in relation to tuberculosis in Cameroon. The international journal of tuberculosis and lung disease: the official journal of the International Union against Tuberculosis and Lung Disease 2016, 20 (9):1199-1204.

[3] Program NTC: [Strategic plan for the fight against tuberculosis in Cameroon, 2015-2019]. In.; 2013: 1-74.

[4] Guo C, Du Y, Shen SQ, Lao XQ, Qian J, Ou CQ: Spatiotemporal analysis of tuberculosis incidence and its associated factors in mainland China. Epidemiology and infection 2017, 145 (12):2510-2519.

[5] Yang Y, Guo C: Seasonality Impact on the Transmission Dynamics of Tuberculosis. 2016, 2016:8713924.

[6] Naranbat N, Nymadawa P, Schopfer K, Rieder HL: Seasonality of tuberculosis in an Eastern-Asian country with an extreme continental climate. The European respiratory journal 2009, 34 (4):921-925.

[7] Parrinello CM, Crossa A, Harris TG: Seasonality of tuberculosis in New York City, 1990-2007. The international journal of tuberculosis and lung disease: the official journal of the International Union against Tuberculosis and Lung Disease 2012, 16 (1):32-37.

[8] Koh GC, Hawthorne G, Turner AM, Kunst H, Dedicoat M: Tuberculosis incidence correlates with sunshine: an ecological 28-year time series study. PloS one 2013, 8 (3):e57752.

[9] Zhang G, Huang S, Duan Q, Shu W, Hou Y, Zhu S, Miao X, Nie S, Wei S, Guo N et al: Application of a hybrid model for predicting the incidence of tuberculosis in Hubei, China. PloS one 2013, 8 (11):e80969.

[10] Khaliq A, Batool SA, Chaudhry MN: Seasonality and trend analysis of tuberculosis in Lahore, Pakistan from 2006 to 2013. Journal of epidemiology and global health 2015, 5 (4):397-403.

[11] Ane-Anyangwe IN, Akenji TN, Mbacham WF, Penlap VN, Titanji VP: Seasonal variation and prevalence of tuberculosis among health seekers in the South Western Cameroon. East African medical journal 2006, 83 (11):588-595.

[12] Simon Brooker CAD, Helen L. Guyatt: Estimating the number of helminthic infections in the Republic of Cameroon from data on infection prevalence in schoolchildren. Bulletin of the World Health Organization 2000, 78 (12):1456-1465.

[13] Olivry JC: Fleuves et rivières du Cameroun: MESRESORSTOM; 1986.

[14] Cameroon Ministry of Transport, Rainfall and mean temperature trends in Yaoundé from 2000 to 2009 Infos bulletin.; 2009: 1-33.

[15] Kalekar PS: Time series Forecasting using Holt-Winters Exponential Smoothing. In. Kanwal Rekhi: Kanwal Rekhi School of Information Technology; 2004: 1-13.

[16] Sidze LK, Mouafo Tekwu E, Kuaban C, Assam Assam JP, Tedom JC, Eyangoh S, Fouda FX, Nolna D, Ntoumi F, Frank
$\mathrm{M}$ et al: Strong decrease in streptomycin-resistance and absence of XDR 12 years after the Reorganization of the National Tuberculosis Control Program in the Central Region of Cameroon. PloS one 2014, 9 (6):e98374.

[17] Soebiyanto RP, Clara WA, Jara J, Balmaseda A, Lara J, Lopez Moya M, Palekar R, Widdowson A, Azziz-Baumgartner E, Kiang RK: Associations between seasonal influenza and meteorological parameters in Costa Rica, Honduras and Nicaragua. Geospatial health 2015, 10 (2):372.

[18] Omonijo AG, Oguntoke O, Matzarakis A, Adeofun CO: A Study of Weather Related Respiratory Diseases in Ecoclimatic Zones African Physical Review 2011, 5 (0003):41-56.

[19] Shilova MV, Glumnaia TV: [Influence of seasonal and environmental factors on the incidence of tuberculosis]. Problemy tuberkuleza i boleznei legkikh 2004 (2):17-22.

[20] Cao K, Yang K, Wang C, Guo J, Tao L, Liu Q, Gehendra M, Zhang Y, Guo X: Spatial-Temporal Epidemiology of Tuberculosis in Mainland China: An Analysis Based on Bayesian Theory. International journal of environmental research and public health 2016, 13 (5).

[21] Oguntoke O, Omonijo AG, Annegarn JH: Influence of meteorology parameters on pulmonary Tuberculosis orbidity in two Eco-climatic zones in Nigeria African journal of health sciences 2012, 20:69-76.

[22] Petersen WF: Tuberculosis: weather and resistance. In: Annual Meeting of the American College of Chest Physicians. Atlantic City, New Jersey; 1943: 403-417.

[23] Pinto CT, Nano FE: Stable, temperature-sensitive recombinant strain of Mycobacterium smegmatis generated through the substitution of a psychrophilic ligA gene. FEMS microbiology letters 2015, 362 (18):fnv152.

[24] Landier J, Constantin de Magny G, Garchitorena A, Guegan JF, Gaudart J, Marsollier L, Le Gall P, Giles-Vernick T, Eyangoh S, Fontanet A et al: Seasonal Patterns of Buruli Ulcer Incidence, Central Africa, 2002-2012. Emerging infectious diseases 2015, 21 (8):1414-1417.

[25] Fares A: Seasonality of tuberculosis. Journal of global infectious diseases 2011, 3 (1):46-55.

[26] Martineau AR, Nhamoyebonde S, Oni T, Rangaka MX, Marais S, Bangani N, Tsekela R, Bashe L, de Azevedo V, Caldwell $\mathrm{J}$ et al: Reciprocal seasonal variation in vitamin $\mathrm{D}$ status and tuberculosis notifications in Cape Town, South Africa. Proc Natl Acad Sci U S A 2011, 108 (47):1901319017.

[27] Margalit I, Block C, Mor Z: Seasonality of tuberculosis in Israel, 2001-2011. The international journal of tuberculosis and lung disease: the official journal of the International Union against Tuberculosis and Lung Disease 2016, 20 (12):1588-1593.

[28] Azeez A, Obaromi D, Odeyemi A, Ndege J, Muntabayi R: Seasonality and Trend Forecasting of Tuberculosis Prevalence Data in Eastern Cape, South Africa, Using a Hybrid Model. International journal of environmental research and public health 2016, 13 (8):1-12. 